\title{
Source term balance in a severe storm in the Southern North Sea
}

\author{
Gerbrant Ph. van Vledder ${ }^{1,2}$ (D) Sander Th. C. Hulst ${ }^{3}$. Jason D. McConochie ${ }^{4}$
}

Received: 1 March 2016 / Accepted: 14 September 2016 / Published online: 19 October 2016

(C) The Author(s) 2016. This article is published with open access at Springerlink.com

\begin{abstract}
This paper presents the results of a wave hindcast of a severe storm in the Southern North Sea to verify recently developed deep and shallow water source terms. The work was carried out in the framework of the ONR funded NOPP project (Tolman et al. 2013) in which deep and shallow water source terms were developed for use in third-generation wave prediction models. These deep water source terms for whitecapping, wind input and nonlinear interactions were developed, implemented and tested primarily in the WAVEWATCH III model, whereas shallow water source terms for depth-limited wave breaking and triad interactions were developed, implemented and tested primarily in the SWAN wave model. So far, the new deepwater source terms for whitecapping were not fully tested in shallow environments. Similarly, the shallow water source terms were not yet tested in large inter-mediate depth areas
\end{abstract}

This article is part of the Topical Collection on the 14th International Workshop on Wave Hindcasting and Forecasting in Key West, Florida, USA, November 8-13, 2015

Responsible Editor: Oyvind Breivik

Gerbrant Ph. van Vledder

g.p.vanvledder@tudelft.nl

1 Delft University of Technology, Delft, The Netherlands

2 Van Vledder Consulting, Olst, The Netherlands

3 BMT ARGOSS, Amersfoort, The Netherlands

4 Shell Global Solutions International B.V, Rijswijk, The Netherlands like the North Sea. As a first step in assessing the performance of these newly developed source terms, the source term balance and the effect of different physical settings on the prediction of wave heights and wave periods in the relatively shallow North Sea was analysed. The December 2013 storm was hindcast with a SWAN model implementation for the North Sea. Spectral wave boundary conditions were obtained from an Atlantic Ocean WAVEWATCH III model implementation and the model was driven by hourly CFSR wind fields. In the southern part of the North Sea, current and water level effects were included. The hindcast was performed with five different settings for whitecapping, viz. three Komen type whitecapping formulations, the saturation-based whitecapping by Van der Westhuysen et al. (2007) and the recently developed ST6 whitecapping as described by Zieger et al. (2015). Results of the wave hindcast were compared with buoy measurements at location K13 collected by the Dutch Ministry of Transport and Public Works. An analysis was made of the source term balance at three locations, the deep water location North Cormorant, the inter-mediate depth location K13 and at location Wielingen, a shallow water location close to the Dutch coast. The results indicate that at deep water the source terms for wind input, whitecapping and nonlinear four-wave interactions are of the same magnitude. At the inter-mediate depth location K13, bottom friction plays a significant role, whereas at the shallow water location Wielingen also depth-limited wave breaking becomes important.

Keywords Wave modelling $\cdot$ SWAN $\cdot$ North Sea $\cdot$ Source term balance $\cdot$ Whitecapping $\cdot$ Wind input $\cdot$ Nonlinear interactions 


\section{Introduction}

Wave modelling in coastal seas poses additional challenges to a modeller in comparison to open ocean wave modelling as the proximity of land and depth effects starts to play a role in the evolution of the wave field. Moreover, orographic effects and changes in surface roughness lead to relative small scale changes in wind speed and wind direction, whereas depth limitations influence the propagation and dissipation of waves. Tidal and wind induced currents and water levels may further affect the evolution of wind waves. The interplay of all of these factors requires a careful assessment of the significance of each of these processes on wave evolution to assess wave model performance and to find sources of errors to improve the wave model. The common way to study these effects is to analyse results in terms of wave spectrum-based integrated parameters like the significant wave height or a mean wave period. A deeper analysis is to analyse results of third-generation spectral wave models in terms of the wave spectra and the under-lying source terms.

Third-generation discrete spectral wave models represent the wave field in terms of the wave spectrum at a large number of locations arranged in a spatial grid. The evolution of these spectra in time and space is governed by the wave action balance equation. The left-hand side of this equation describes the change in time and the effects of propagation in spectral and spatial space. The right-hand side describes the processes for growth of wave energy by wind, dissipation by whitecapping and depth effects $\left(S_{\text {bot }}, S_{\text {brk }}, \cdots\right)$ and non-linear triad and quadruplet interactions exchanging wave energy between various wave components. The quality of a wave hindcast or forecast is determined by many factors. Roland and Ardhuin (2014) suggest a hierarchy of sources of error of which the forcing by wind, currents and water level variations come first, followed by the quality of the source terms and finally numerical effects. This is not a generic hierarchy as the order of importance depends on the local situation. For instance, for a long-period, swell travelling over the ocean under weak winds the quality of the numerical scheme is dominant.

In coastal areas, local wind can be affected by orographic effects as discussed by Cavaleri and Bertotti (2004) and Pallares et al. (2014) in the Mediterranean Sea, but also by abrupt changes in surface roughness after land-sea transitions where the wind field slowly increases with fetch (Taylor and Lee 1984; Morris et al. 2015). In shallow coastal areas, tidal effects may become critical in reproducing the conditions as currents, depth limitations and water levels lead to small scale variations in time and space of the wave field (Van der Westhuysen et al. 2012; Ardhuin et al. 2012). Especially in areas where waves are depth-limited any error in computational depth, i.e. the sum of bottom level and water level, directly translates into the predicted wave height (Salmon et al. 2015).

In severe storms or hurricanes with wind speeds exceeding $30 \mathrm{~m} / \mathrm{s}$, it is now generally acknowledged that wind drag does not increase linearly with wind speed as proposed by Wu (1982), although it must said that Wu (1982) did not consider such extreme wind speeds. Already Blake (1991) surmised that wind drag does not grow indefinitely linearly with wind speed. A cap on wind drag was introduced by Khandekar et al. (1993) to improve wave predictions in hurricane conditions. A decade later, this notion was confirmed experimentally by Powell et al. (2003) for hurricane conditions, who even suggested that wind drag decreases for wind speeds exceeding $30 \mathrm{~m} / \mathrm{s}$. Parameterisations of this effect were proposed by Hwang (2011), Holthuijsen et al. (2012) and Zweers et al. (2015). It is noted that no firm evidence exists about the behaviour of wind drag for wind speeds above $30 \mathrm{~m} / \mathrm{s}$ (Stoffelen 2015, personal communication) and that a conservative approach is to cap the wind drag at its maximum value reached at a wind speed of about $30 \mathrm{~m} / \mathrm{s}$. For the storm considered in the present analysis, it is noted that the maximum wind speed did not exceed $30 \mathrm{~m} / \mathrm{s}$.

The final aim of developers of third-generation wave prediction model is to represent all physical processes affecting the growth and decay of wave energy on the basis of firstprinciples to allow the spectrum to evolve without any constraints on the spectral shape. This aim, however, is still out of reach and many source terms still contain many empirically based functional relationships and coefficients. For deep water, it is generally acknowledged that source terms are required for wind wave growth, whitecapping dissipation and nonlinear quadruplet interactions exchanging energy between different wave components. As waves enter shallow water also bottom friction, depth induced breaking, dissipation by vegetation and opposing currents, nonlinear triad interactions and bottom scattering start to play a role in the source term balance.

The development of third-generation wave prediction models became possible with the introduction of the Discrete Interaction Approximation (DIA) by Hasselmann et al. (1985) to estimate the nonlinear transfer of wave energy between pairs of four wave numbers in spectral space having the same number of degrees of freedom as the discrete spectrum. These quadruplet interactions not only play an important role in the evolution of wind waves (Young and Van Vledder 1993), but also their numerical evaluation is the subject of many studies. Of all source terms, the one for the nonlinear four-wave interactions has a special place; it is the only source term for which a closed theoretical solution based on first principles exists, although in terms of a complicated sixfold integral in a three-dimensional wave number manifold. This feature makes it very time consuming to evaluate this source term, making it unfeasible 
for practical and operational applications. To overcome this limitation, Hasselmann et al. (1985) developed the Discrete Interaction Approximation (DIA) allowing the development of the first operational third-generation wave prediction model WAM (WAMDI 1988). Inclusion of the DIA in a source term packages implies that tuning is needed to be able to reproduce empirical growth curves or other types of measurements data. This process, however, implies that deficiencies of the DIA are usually compensated by tuning of the other source terms (Van Vledder et al. 2000).

The WAM model (WAMDI 1988) contains also source terms for wind input according to the Snyder et al. (1981) parameterisation and whitecapping dissipation according to Komen et al. (1984, 1994). For shallow water applications, a bottom friction term according to the JONSWAP (Hasselmann et al. 1973) was added. Since the WAM model, many new source terms have been proposed, especially regarding the whitecapping dissipation. Tolman and Chalikov (1996) proposed a new set of source terms for application in the WAVEWATCH III model (Tolman 2009; Tolman et al. 2014). One of the shortcomings of the Komen et al. (1984) or its modified form by Komen et al. (1994) is the use of an overall mean wave steepness. This is especially problematic in mixed sea conditions where such an approach leads to an over-estimation of dissipation for the lower frequencies and an under-estimation of dissipation for the higher frequencies. Rogers et al. (2003) analysed the use of this whitecapping source term in a range of conditions and recommended a certain weighting of the mean steepness.

A first step to replace the Komen type dissipation function was made by Alves and Banner (2003) who introduced the concept of local saturation. A modification to this method was proposed by Van der Westhuysen et al. (2007) who scale the dissipation rate with the relative excess of wave energy above a certain threshold. It was also realized that relative short waves riding on longer waves experience enhanced dissipation by straining effects as shown by Banner et al. (1989) and Melville et al. (2002). Based on this idea, a cumulative steepness dissipation term was proposed by Hurdle and Van Vledder (2004). Young and Babanin (2006) arrived at a similar conclusion and also proposed a cumulative source term. Observations of swell dissipation over long distances resulted in a separate dissipation term for swell associated with turbulence (Ardhuin et al. 2009) in the upper layer of the ocean. Significant progress was made by Ardhuin et al. (2010) who combined the effects of local saturation (but scaled with the absolute excess of wave variance), cumulative effects and a separate swell dissipation term. Some corrections to the Ardhuin et al. (2010) were made by Leckler et al. (2013). The formulations by Ardhuin et al. (2010) are referred to as the ST4 source term package in the WAVEWATCH III model. Along similar lines, Rogers et al. (2012), Babanin et al. (2010) and Zieger et al. (2015) developed an observation-based whitecapping source term in combination with a new wind input source term. These formulations are referred to as the ST6 source term package in the WAVEWATCH III model. The common elements of these new source terms are the use of local wave saturation, a cumulative wave steepness term and a separate treatment of low-frequency swell waves by viscous damping against the atmosphere or water turbulence.

Progress in the development of accurate and efficient solvers for the nonlinear quadruplet interactions is slow. An important step in extending the DIA was proposed by Van Vledder (2001) who suggested a method of adding additional wave number configurations of arbitrary shape. This method was exploited by Tolman (2012) who derived a generalized multiple DIA (GMD) showing good performance for a large number of academic and non-stationary field cases. A drawback of the GMD is its cumbersome calibration using a genetic algorithm (Tolman and Grumbine 2012) in combination with a pre-selected set of source terms. This way of deriving limits its general applicability, although these limits are not yet known. Other ways of arriving at optimal methods for computing these interactions are discussed in Van Vledder (2012), in which 'optimal' should be interpreted as being both sufficiently accurate for nonstationary situations and computationally attractive from an operational point of view.

Spatial variations in depth cause changes in the phase velocity producing wave refraction, while changes in group velocity cause shoaling and a steepening of individual waves. The spatial scale of depth changes is of importance for choosing stable and accurate numerical schemes for wave propagation. This is especially true for areas with steep gradients in bathymetry which, depending on the numerical scheme, may require limiters, see for instance Dietrich et al. (2013). In general, such problems can easily be solved by increasing the spatial resolution or smoothing the bathymetry.

The above summary shows that spectral wave modelling involves a large number of issues to arrive at a successful wave hindcast. One of these issues concerns the source term balance. In semi-enclosed seas like the North Sea, spatial variations in source term balance exist and knowledge of this balance may help in the interpretation of model results and guide researchers to improve the wave model. In deep open ocean conditions only the source terms for wind input, whitecapping dissipation and non-linear interactions are relevant, and it is generally assumed that they are more or less of equal magnitude. For the North Sea, the source term balance was investigated by Bouws and Komen (1983) to arrive at an estimate of JONSWAP type bottom friction during storm conditions. The January 1976 storm considered by Bouws and Komen (1983) was reanalysed 
by Zijlema et al. (2012) who showed that one value for the JONSWAP bottom friction rate suffices for both wind sea and swell conditions in combination with a wind speed dependent wind drag coefficient. In shallow water or close to the coast, this balance may change. An interesting example was presented by Holthuijsen et al. (2008) who showed that the inverse of the normalized source term magnitude is a measure of the time scale of spectral changes according to a certain source term or equivalently a certain physical process. Such knowledge may help in choosing measurement locations to focus on understanding a certain physical process as represented by a specific source term.

For many coastal applications, information on the amount of low-frequency energy, often represented by swell waves, is important. For instance, low-frequency waves affect the motions of large vessels on their way to the Port of Rotterdam. A good prediction of this low-frequency wave energy is required for the prediction of entrance windows to ensure sufficient keel clearance in the shallow entrance channel. To that end, the low frequency wave height $H_{\mathrm{E} 10}$ (i.e. the parameter HSWELL in the SWAN model) is used as a predictor based on the wave variance present in all discrete frequencies up to and including $0.1 \mathrm{~Hz}$. This parameter is difficult to predict as the wave energy in these frequency bands is affected by inaccuracies in numerical propagation schemes, inaccuracies in whitecapping dissipation (especially by those based on using a mean wave steepness), bottom friction and nonlinear wave-wave interactions. Moreover, an inaccurate influx of swell energy from the Atlantic Ocean may contribute to the prediction error which may further detoriated by inaccuracies in numerical propagation schemes. A practical problem so far is that present SWAN model applications were tuned in terms of an overall significant wave height $H_{\mathrm{m} 0}$ and spectral periods like $T_{\mathrm{m} 01}$ and $T_{\mathrm{m}-1,0}$. Therefore, more attention should be paid parameterisations of physical processes that have a relatively large influence on the frequency distribution of wave energy like whitecapping and non-linear interactions.

Part of this work has been carried in the framework of the NOPP project (Tolman et al. 2013) and in the framework of a project to improve the prediction with SWAN of the low-frequency wave energy near the entrance channel to the Port of Rotterdam in collaboration with Deltares, Delft University of Technology and Rijkswaterstaat. In the NOPP project new deep water source terms were primarily developed within the framework of the WAVEWATCH III model, and where new shallow water source terms were primarily developed within the framework of the SWAN model. It is the aim of the SWAN model development group to include these new wind input, whitecapping and swell dissipation source terms from the WAVEWATCH III community into the SWAN model and vice versa. An important advantage of this approach is increased consistency between both models which may be beneficial when SWAN is nested into the WAVEWATCH III model for coastal applications. The inclusion of the ST6 source term package, as described by Zieger et al. (2015) is a first step to make these models mutually consistent.

This paper presents the first results of such a study based on the analysis of a wave hindcast of a severe storm that occurred in the North Sea. The hindcast results were compared against buoy measurements collected at station K13 located in the southern North Sea and collected by the Dutch Ministry of Transport and Public Works. For the hindcast, the third-generation wave prediction model SWAN, version 41.10, was setup for the North Sea on a fine regular spherical grid. Spectral wave boundary conditions were obtained from a WAVEWATCH III implementation of the Atlantic Ocean. An analysis was made of the impact of various source term packages on the source term balance. We applied the Komen et al. $(1984,1994)$ whitecapping dissipation with two settings to scale the dissipation rate (cf. Rogers et al. 2003); one with an increased bottom friction; the saturation based whitecapping dissipation according to Van der Westhuysen et al. (2007); and the recently developed observation-based wind input and whitecapping dissipation as described in Zieger et al. (2015). The source term balance is illustrated by means of spatial maps of source term magnitudes as well as time series of source term with magnitudes at three locations; one in deep water, one in inter-mediate water depth and a shallow water location. These results were compared with those obtained by Bouws and Komen (1983). As the prediction of low-frequency waves $(f<$ $0.1 \mathrm{~Hz}$ ) is also of interest, we also present results of the corresponding low-frequency wave height $H_{\mathrm{E} 10}$.

\section{Wave model setup}

\subsection{The North Sea}

The North Sea is a partially enclosed sea with a decreasing depth while moving from north to south. Along the Danish and Dutch coasts, the water depth slowly decreases up to the coast line, but along the east coast of England and along the Belgium coast many shallow ridges exist causing small scale variations in wave characteristics. The North Sea is connected to the Norwegian Sea and the Atlantic Ocean where occasional swell systems may penetrate and travel south-wards providing mixed sea states. The Dover Strait allows some waves to enter the southern part of the North Sea. Figure 1 shows the bathymetry of the wave model setup covering the North Sea and part of the Atlantic Ocean as used in our wave model implementation. 


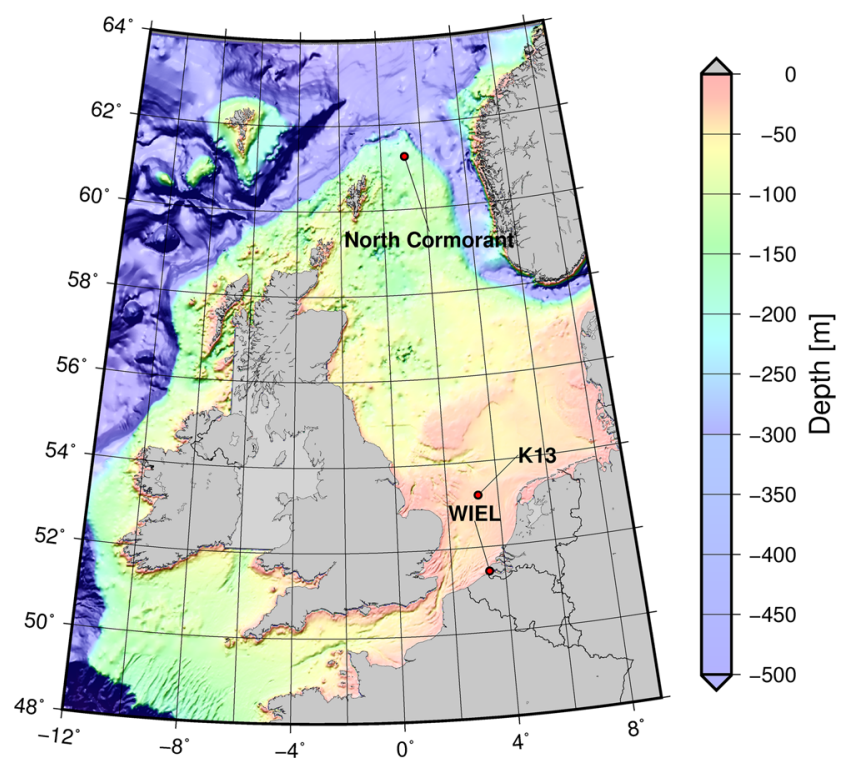

Fig. 1 Bathymetry of the North Sea, depth in m. The measurement locations NCO, K13 and WIEL are indicated with red dots

\subsection{Computational grid and output location}

For hindcasting storms on the North Sea, a computational grid was defined covering the North Sea and part of the Atlantic Ocean. It is shown in Fig. 1 and ranges from $12^{\circ} \mathrm{W}$ to $9^{\circ} \mathrm{E}$ and from $48^{\circ} \mathrm{N}$ to $64^{\circ} \mathrm{N}$. The Irish Sea has been left out from our grid to save active grid points. Sensitivity tests were carried out to arrive at a sufficiently fine spatial grid with $\Delta \lambda=0.05^{\circ}$ and $\Delta \varphi=0.0333^{\circ}$ resulting in a grid of 421 by 481 grid points in longitude and latitude direction, respectively.

For the present study, wave model results are presented at three locations; the deep water location North Cormorant, the inter-mediate depth location K13 and the shallow water location Wielingen. These three locations are shown with dots in Fig. 1. Their name, geographical coordinates and water depth are given in Table 1.

\subsection{The SWAN wave model}

SWAN (Simulating WAves Nearshore) model is a thirdgeneration wave model based on the action density balance equation. The theoretical and numerical background of

Table 1 Name, position and bottom level of output locations

\begin{tabular}{llll}
\hline Name & $\lambda\left({ }^{\circ}\right)$ & $\varphi\left({ }^{\circ}\right)$ & depth $(\mathrm{m})$ \\
\hline North Cormorant & 1.149 & 61.240 & 160 \\
K13 & 3.2203 & 53.128 & 28 \\
WIEL & 3.412 & 51.427 & 8 \\
\hline
\end{tabular}

SWAN is described in Booij et al. (1999), and Zijlema and Van der Westhuysen (2005). As SWAN is still under development, the most recent scientific and technical background information can be found in the SWAN technical manual (SWAN team, 2016). In the SWAN model, the evolution of the action density $(N)$ is governed by the action balance equation:

$$
\frac{\partial}{\partial t} N+\frac{\partial}{\partial x}\left(c_{x} N\right)+\frac{\partial}{\partial y}\left(c_{y} N\right)+\frac{\partial}{\partial \sigma}\left(c_{\sigma} N\right)+\frac{\partial}{\partial \theta}\left(c_{\theta} N\right)=S(\sigma, \theta ; x, y, t)
$$

where $c_{x}$ and $c_{y}$ are the $x$ - and $y$-components of the group velocity corrected for propagation on a current. $N=E / \sigma$ is the action density and is related to energy density $E$ by division through the intrinsic frequency $\sigma$. The quantities $c_{\sigma}$ and $c_{\theta}$ are the propagation velocities in spectral space $(\sigma, \theta)$. The right-hand side contains the total source term $S(\sigma, \theta ; x, y, t)$, representing the effects of generation, dissipation and nonlinear wave-wave interactions. It consists of deep water and shallow water source terms.

$$
\begin{array}{r}
S(\sigma, \theta)=S_{\text {inp }}(\sigma, \theta)+S_{\text {wcap }}(\sigma, \theta)+S_{\mathrm{nl} 4}(\sigma, \theta) \\
+S_{\text {brk }}(\sigma, \theta)+S_{\text {fric }}(\sigma, \theta)+S_{\mathrm{nl} 3}(\sigma, \theta)
\end{array}
$$

These terms denote, respectively, the deep water source terms for generation due to wind input, dissipation due to whitecapping, nonlinear quadruplet wave-wave interactions, and the shallow water source terms for dissipation due to depth-induced wave breaking, bottom friction, and triad wave-wave interactions. Wind input is based on the parameterisation by Snyder et al. (1981).

The focus of this paper is to assess the effect of applying different whitecapping formulations. Therefore, the most important characteristics of these formulations are summarized below. The oldest spectral whitecapping formulation is based on the pulse model of Hasselmann (1974), as adapted by the WAMDI group (1988) and Janssen (1991):

$S_{\text {wcap }}(\sigma, \theta)=-\Gamma \times \tilde{\sigma} \times \frac{k}{\tilde{k}} \times E(\sigma, \theta)$

where $k$ is wave number, $\tilde{\sigma}$ and $\tilde{k}$ denote a mean frequency and a mean wave number, respectively, $\Gamma$ is a steepnessdependent coefficient which depends on the overall wave steepness. This steepness-dependent coefficient was generalized by Günther et al. (1992):

$\Gamma=C_{\mathrm{ds}} \times\left((1-\delta)+\delta \times \frac{k}{\tilde{k}}\right) \times\left(\frac{\tilde{s}}{\tilde{s}_{P M}}\right)^{p}$

The coefficients $C_{\mathrm{ds}}, \delta$ and $p$ are tuneable coefficients, $\tilde{s}$ is the overall wave steepness, and $\tilde{s}_{P M}=0.055$ is the value of $\tilde{s}$ for the Pierson- Moskowitz spectrum (Pierson and Moskowitz 1964). 
The formulation by Van der Westhuysen et al. (2007) is expressed as:

$S_{\text {wcap }}(\sigma, \theta)=-C_{d s} \times\left[\frac{B(k)}{B_{r}}\right]^{p / 2} \times g^{\frac{1}{2}} k^{\frac{1}{2}} E(\sigma, \theta)$

with $C_{\mathrm{ds}}$ and $p$ tuneable coefficients, $g$ is the gravitational acceleration, $B$ is the saturation threshold and where $B(k)$ is computed from the directionally integrated wave spectrum as follows:

$B(k)=c_{g} k^{3} E(\sigma)$

with $c_{g}$ the group velocity and $k$ the wave number.

Donelan et al. (2005, 2006), Rogers et al. (2012), Babanin et al. (2010) and Zieger et al. (2015) developed an observation-based whitecapping dissipation and wind input term. The whitecapping part is composed of two components, as formulated in action density $N(k, \theta)$

$S_{\mathrm{ds}}(k, \theta)=\left[T_{1}(k, \theta)+T_{2}(k, \theta)\right] N(k, \theta)$

Where $T_{1}$ is the inherent breaking term and $T_{2}$ accounts for the cumulative effect of short-wave breaking due to longer waves at frequencies lower than the peak frequency. In contrast to the Van der Westhuysen et al. (2007) dissipation term, the inherent breaking term is scaled with the excess $\Delta$ of action density above a certain threshold $N_{T}(k)$. This excess can be written as $\Delta=N(k)-N_{T}(k)$. The $T_{1}$ term can be written as:

$T_{1}(k)=a_{1} A(k) \frac{\sigma}{2 \pi}\left[\frac{\Delta(k)}{N(k)}\right]^{p_{1}}$

And the cumulative term $T_{2}$ can be written as:

$T_{2}(k)=a_{2} \int_{0}^{k} A(k) \frac{c_{g}}{2 \pi}\left[\frac{\Delta(k)}{N(k)}\right]^{p_{2}}$

with $a_{1}, a_{2}, p_{1}$ and $p_{2}$ tuneable coefficients and $A$ is a measure for the directional narrowness. Further details of all whitecapping dissipation formulations can be found in the referred articles.

The four-wave interactions are represented by the discrete interaction approximation of Hasselmann et al. (1985) using their default settings. Running the SWAN model with more accurate nonlinear interaction, e.g. the WRTimplementation of Van Vledder (2006) is still unfortunately unfeasible for operational applications due to its high computational requirements.

Bottom friction is represented by the so-called JONSWAP bottom friction formulation of Hasselmann et al. (1973):

$S_{\text {fric }}(f, \theta)=-\chi \frac{\rho g k^{2}}{(2 \pi f)^{2} \cosh ^{2}(k d)} E(f, \theta)$

in which $f$ is frequency, $\theta$ is direction, $k$ is wave number, $d$ is depth, and the bottom friction coefficient $\chi=0.038 \mathrm{~m}^{2}$ $\mathrm{s}^{-3}$ as recommended by Zijlema et al. (2012). We chose the latter value for most of our computations.

Depth-limited wave breaking was modelled using the bore model formulation of Battjes and Janssen (1978) using the recommended settings of $\alpha=1.0$ and $\gamma=0.73$. Lastly, nonlinear triad interactions were modelled according to the LTA method of Eldeberky (1996). It is noted, however, that triad interactions played only a marginal role in the present hindcast study. This is mainly due to the fact that the shallow coastal areas are not well resolved in the applied model schematisation. Some tests computations were also carried out with the recently developed consistent triad formulation of Salmon et al. (2016), but only minor differences were found in the present hindcast.

\subsection{Forcing of the wave model}

The SWAN wave model is forced with hourly CFS wind fields (Saha et al. 2010), calibrated against satellite data (Hulst and Van Vledder 2013) with a spatial resolution of $0.0245^{\circ}$ by $0.0244^{\circ}$ in longitudinal and meridional direction. The wave model computations were carried with a fixed bathymetry. For the southern North Sea, spatial and temporal water level and current fields were included. These fields were produced by the operational CSM and ZUNO flow models for the Southern North Sea of Deltares. In view of the applied grid resolution for the wave model, fine scale details of currents in, e.g. tidal inlets, could not be resolved. Spectral wave boundary conditions along the western and northern grid boundaries were obtained from BMTAs global WAVEWATCH III implementation at three hourly intervals.

The SWAN model was run in non-stationary mode with a time step of $10 \mathrm{~min}$. Some sensitivity runs were performed to assess the effect of smaller and larger time steps. It was found that differences in results for wave heights and periods were smaller than a few percent, which was deemed sufficient for the present hindcast. Thirty-eight (38) discrete frequencies ranged from 0.03 to $1 \mathrm{~Hz}$ with a logarithmic spacing of $f_{i+1}=1.1 f_{i}$, as required by the DIA, and the directional resolution was $10^{\circ}$ yielding 36 directions.

Of special interest in the present study is the ability of the SWAN model to predict the low-frequency wave height, as this quantity is of particular interest for prediction of wave-induced motions affecting the keel clearance of large ships on their way to the Port of Rotterdam. The low-frequency wave height is computed from the frequency spectrum according to:

$H_{\mathrm{E} 10}=4 \sqrt{\int_{f_{\text {low }}}^{0.1} E(f) d f}$ 


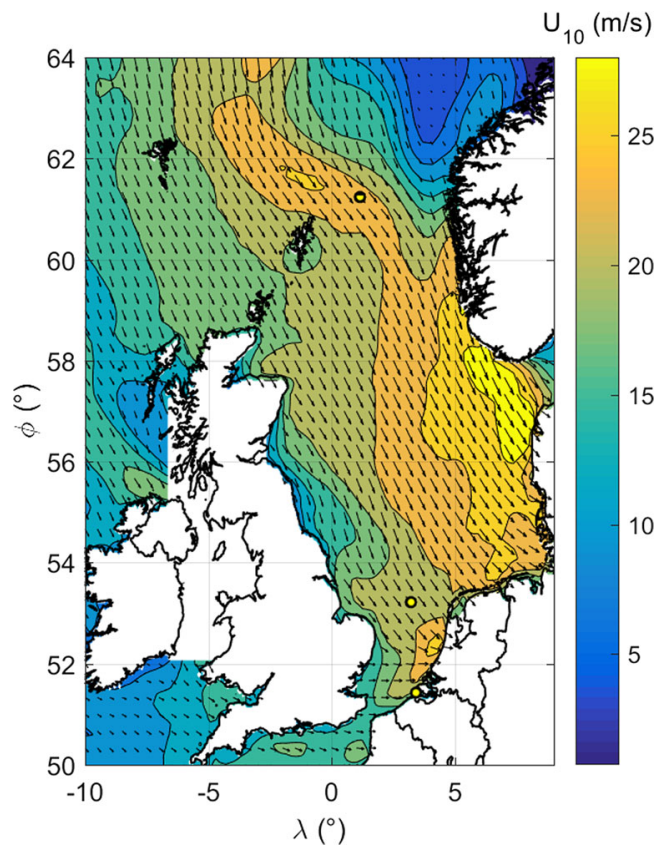

Fig. 2 Spatial variation of wind speed of the Santa Claus storm at 5 December 2013, 15:00 h. The arrows indicate the wind direction. The dots are the three output locations

in which $f_{\text {low }}$ is the lowest model frequency of the wave model.

\subsection{The December 2013 storm}

On 5 and 6 December 2013, a severe winter storm passed over the North Sea causing widespread damage in the surrounding countries. The depression followed a path south of Greenland and Iceland, passing just north of Scotland towards the south of Norway and Sweden. Wind speeds reached hurricane force with a highest hourly wind speed of $130 \mathrm{~km} / \mathrm{h}$ in the north of Jutland, Denmark. As the peak of the storm coincided with spring tide dangerously high water levels were reached along the coasts of Belgium, the Netherlands, Germany and Denmark, with some flooding in low-lying coastal areas. This storm generated significant wave heights up to $5 \mathrm{~m}$ in front of the Dutch coast. Further north, significant wave heights up to $10 \mathrm{~m}$ were measured. In the Netherlands, this storm is known as the Sinterklaas (Santa Claus) storm, whereas in Germany the name Xavier is used. Figure 2 shows a snapshot of the spatial variation of speed magnitude and direction at the peak of this storm on 5 December 2013, 15:00 h.

Figure 3 shows the time variation of the observed and CFS-based wind speed $U_{10}$ (upper panel) and wind direction $\theta_{w}$ in the nautical convention (lower panel) for the December 2013 storm at location K13 in the southern North Sea. The peak wind speed peaked just above $20 \mathrm{~m} / \mathrm{s}$, and the wind direction was predominantly from the West to the
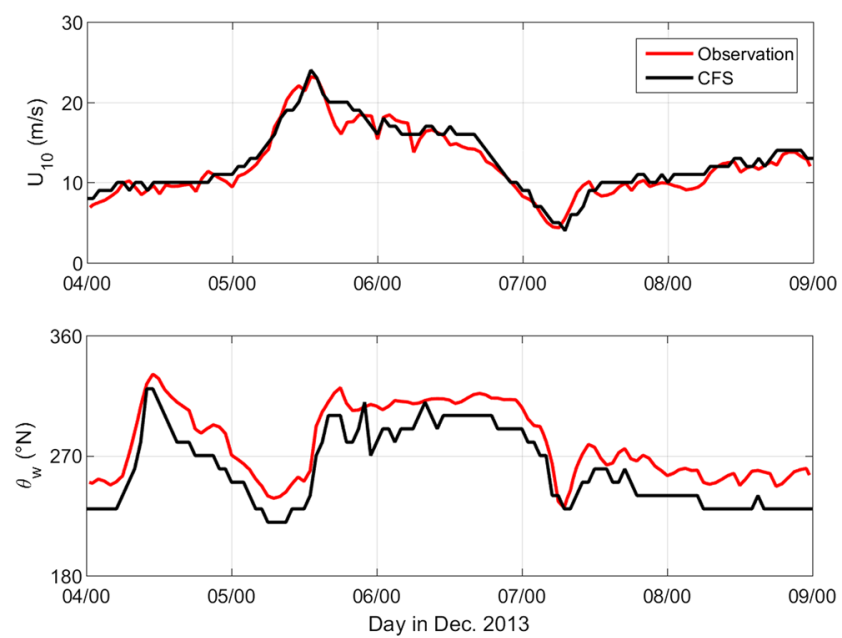

Fig. 3 Temporal variation of wind speed observed and CFS-based wind speed (upper panel) and wind direction (lower panel) for the December 2013 storm

North-West. The wind speeds agree fairly well, whereas at K13 the simulated wind directions are systematically biased by about $20^{\circ}$ in counter-clockwise direction. Inspection of observed and simulated wind directions at more northerly locations suggests that this bias seems to be a local effect, possible due to land effect of England on the simulated winds.

\section{Results of the wave hindcast}

The SWAN wave model was first run with the present (status fall 2015) default settings for whitecapping dissipation, viz. the Komen type dissipation using $\delta=1$ as recommended by Rogers et al. (2003) and a constant JONSWAP bottom friction coefficient of $C_{f, J O N}=0.038 \mathrm{~m}^{2} \mathrm{~s}^{-3}$ as recommended by Zijlema et al. (2012). Hereafter, model runs were applied using the Komen-type whitecapping with $\delta=0$, the saturation-based whitecapping formulation of Van der Westhuysen et al. (2007) and the recently developed ST6 whitecapping formulation, all with a bottom friction coefficient of $C_{f, J O N}=0.038 \mathrm{~m}^{2} \mathrm{~s}^{-3}$. Finally, the first run was repeated with the previously used higher value for the bottom friction coefficient of $C_{f, J O N}=0.067 \mathrm{~m}^{2} \mathrm{~s}^{-3}$, which is the value originally recommended by Bouws and Komen (1983). A summary of the physical settings of the SWAN model is given in Appendix A.

The results of the first source term package are presented as the time variation of significant wave height $H_{\mathrm{m} 0}$, the percentage of the low frequency wave height $H_{\mathrm{E} 10}$ with respect to the significant wave height $H_{\mathrm{m} 0}$ and the mean wave period $T_{m-1,0}$, in literature also referred to as the 

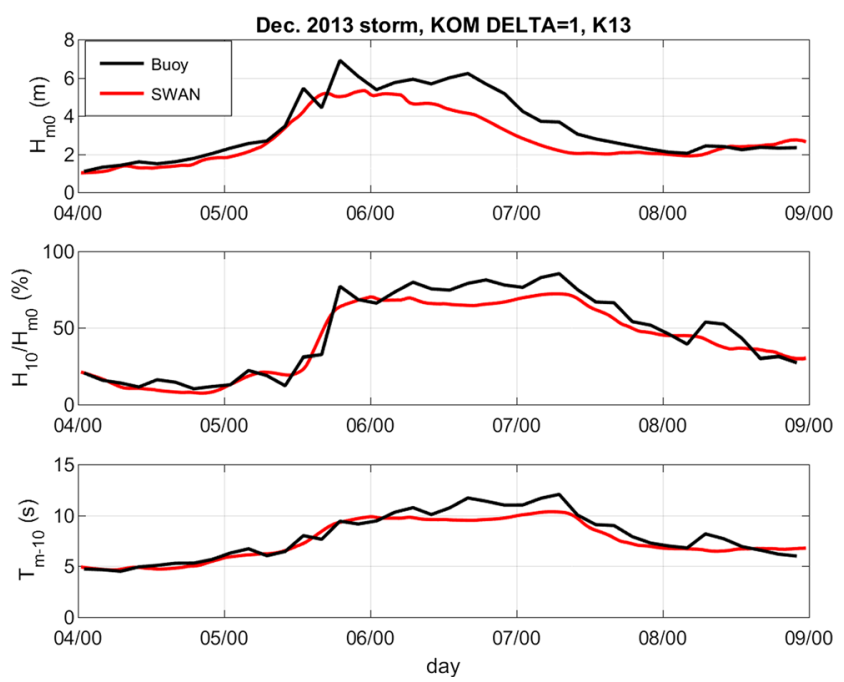

Fig. 4 Temporal variation of significant wave height $H_{\mathrm{m} 0}$, percentage of low-frequency wave height $H_{\mathrm{E} 10}$ with respect to $H_{\mathrm{m} 0}$, and the spectral period $T_{m-1,0}$ for the Dec. 2013 storm at location K13. Buoy data (black line), SWAN results (red line)

energy period $T_{E}$. The computational results of our reference settings are shown in Fig. 4 with red lines. The black line represents the observed values.

The results in Fig. 4 show a systematic under-prediction of the significant wave height $H_{\mathrm{m} 0}$, and a small underprediction of the spectral period $T_{m-1,0}$ at the peak of the storm. The predicted percentage of low-frequency wave height is slightly underestimated during the peak of the storm. It is noted that these results were obtained with the default settings of the SWAN model. For this particular storm results can be improved by tuning, but that has not been done for this study as our aim is to compare effects of different source term packages on model results.

The spatial variation of significant wave height $H_{\mathrm{m} 0}$ at 5 December 2013, 15:00 h is shown in the left panel of Fig. 5. In the southern part of the North Sea waves are affected by depth as can be seen by the spatial variation of the wave height over depth ratio $H_{m 0} / d$. This ratio is shown in the right panel of Fig. 5 for the same moment of time as the $H_{\mathrm{m} 0}$ field on the left. Depth effects are noticeable just north of and over the Doggersbank and close to the coasts of the Netherlands, Germany and Denmark.

The results in Fig. 5 also show that the largest wave height over depth ratio is about 0.3 and mainly due to bottom friction effects (see Fig. 6). Only close to the coast of Denmark some noticeable effects of surf-breaking were found (not shown here) leading to $H_{m 0} / d$ values above 0.3. It is expected that closer to shore this ratio will increase to values of about 0.5 in depth-limited situations (e.g. Salmon et al., 2015). Such values, however, were not encountered in our computations as shallow coastal areas are not sufficiently fine resolved in the present model setup. Further refinements of spatial resolution, a better resolved bathymetry in shallow coastal areas in combination with applying the recently developed $\beta-k d$ scaling (Salmon et al. 2015) of the $\gamma$ parameter may shed light on the source term balance in shallow water.

A better understanding of the performance and behaviour of third-generation spectral wave models is to inspect the source terms that are part of the wave action balance equation. A usual approach is to compute and visualize these terms for academic spectra. Although this may be necessary for their development, it is not sufficient to judge and validate their behaviour as nonlinear four-wave interactions
Fig. 5 Snapshot of spatial variation of significant wave height $H_{\mathrm{m} 0}$ and mean wave direction (left panel), and ratio of significant wave height over depth $H_{m 0} / d$ on 5 December 2013, 15:00 h UTC. The arrows indicate the mean wave direction
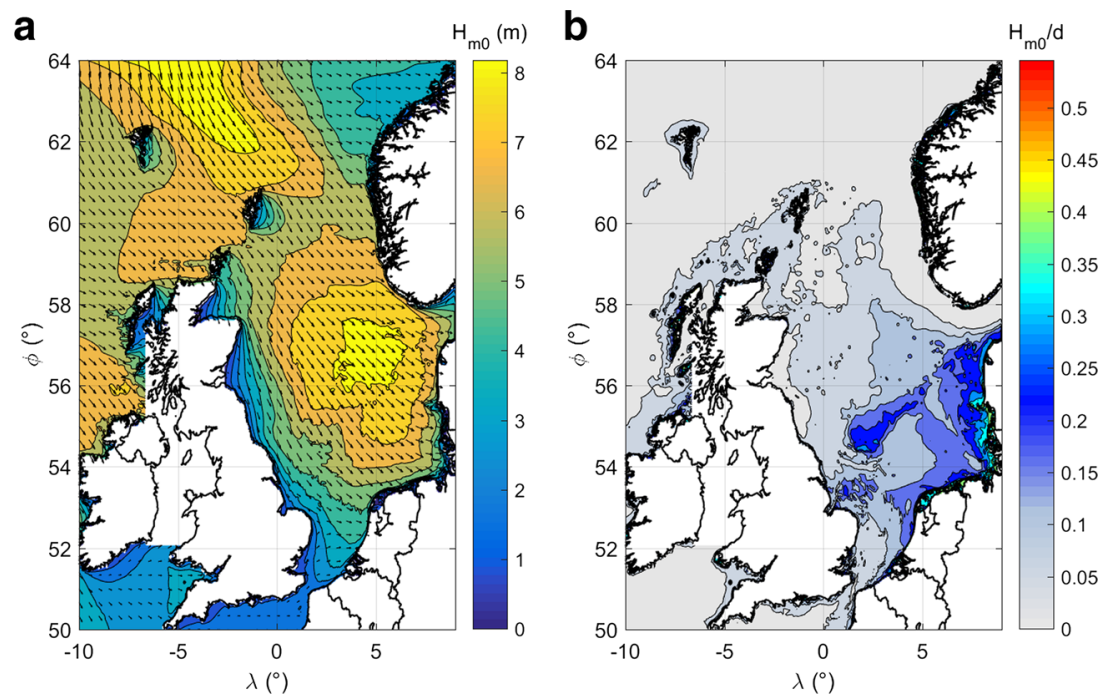
quickly adapts the spectral shape during spatial or temporal evolution of the spectrum. This holds especially for the development of parameterisations of the nonlinear fourwave interactions (cf. Van Vledder, 2012) where its effect on spectral wave evolution is more determining than its ability to reproduce the exact nonlinear transfer for an academic (JONSWAP) spectrum.

There are different ways of looking at the source term balance during wave evolution. The most basic level is to visualize the temporal evolution of an individual source term at a specific location as a function of frequency (or wave number) and direction. This approach produces a huge amount of information which is difficult to interpret. An easier way is to inspect either the directionally integrated or the frequency integrated source terms as a function of time at a certain location. The simplest way, however, is to consider the source term magnitude, obtained by integrating it with respect to frequency and direction.

For a certain source term $S_{S}$ its magnitude $M_{S}$ is computed as the integral over frequency and direction according to:

$$
M_{S}=\operatorname{sign}\left(S_{S}\right) \times \int_{0}^{2 \pi} \int_{f_{\text {low }}}^{f_{\text {high }}}\left|S_{S}(f, \theta)\right| d f d \theta
$$

in which $f_{\text {low }}$ and $f_{\text {high }}$ are the lowest and highest discrete model frequencies. The sign ensures that the magnitude of dissipation source terms becomes negative. As the total integral over the nonlinear interaction source terms is zero by definition, their absolute values are used to obtain an estimate of their importance. It is noted that this only holds when the integration range is from 0 to infinity. In practise, the total integral is non-zero as the interactions are only computed over a finite frequency range and some minor residues may be generated as the contributions of the spectral tail are not accounted for. In the present study, we used $f_{\text {low }}=0.03 \mathrm{~Hz}$ and $f_{\text {high }}=1 \mathrm{~Hz}$.

Holthuijsen et al. (2008) showed that the reciprocal value of normalized (with $m_{0}$ ) source term magnitude can be considered as a time scale with which a certain (parameterized) physical process influences spectral evolution. Their work showed the various processes at work in a tidal inlet connecting the North Sea and the Dutch Wadden Sea.

To visualize the source terms in our model simulation, we used the recently added functionality in the SWAN model (version 41.01 and higher) to output source term magnitudes as fields (BLOCK output) or in table format at selected output locations, both in stationary and in non-stationary mode. Individual source terms can be output as frequencydirection or as frequency dependent spectra using the TEST option in so-named S2D and S1D output files in selected output (test) locations. In stationary mode, these terms are output per iteration, whereas in non-stationary mode they are output per time step. It is noted that in the TEST output also source term magnitudes can be output in so-named PAR-files. Similar output options are also available in other third-generation wave models.

The spatial variation of source term magnitudes for wind input $\left(S_{\text {wind }}\right)$, whitecapping dissipation $\left(S_{\text {wcap }}\right)$, four-wave interactions $\left(S_{\mathrm{n} 14}\right)$ and bottom friction $\left(S_{\text {fric }}\right)$ are shown with equal scales in Fig. 6. This figure shows strong similarities in the spatial distribution of magnitude of wind input and white-capping dissipation, suggesting that their magnitudes are of the same order. This is as expected as both terms scale in proportion to the variance density spectrum, but also because the nonlinear term conserves energy. The variation of the four-wave nonlinear interaction term is also similar but less pronounced. Significant bottom friction is confined to the relatively shallow areas on the Doggersbank and the shallow coastal areas of the Netherlands, Germany and Denmark. The source term magnitude of depth-limited wave breaking $S_{\text {brk }}$ and triad interaction $S_{\text {nl3 }}$ are not shown as they as confined to only a few shallow coastal areas which are not well resolved in the applied grid.

The results shown in Fig. 6 are useful as they show the spatial variation of source term magnitudes, but they do not clearly show their relative magnitude and how they make up the source term balance. Time series with this information were extracted from the SWAN model runs at the output locations and stored in tables. Figure 7 shows the source term balance for the December 2013 storm at location K13. Note that the magnitude of the triad source term was not plotted as its magnitude was insignificant in the output locations considered in this study.

The results show that the absolute magnitude of wind input and whitecapping are more or less equal during the storm, indicating a near equilibrium situation. The total magnitude of the nonlinear interaction term is slightly lower than the wind input term. Bottom friction becomes significant, but not dominant, after the peak of the storm as this process is strongly correlated with wave height, whereas depth-limited wave breaking does not play a role at this location during this storm. It can also be seen that (positive) wind input is almost cancelled by the sum of the (negative) dissipation terms. These results are in qualitative agreement with results found by Bouws and Komen (1983), but not quantitatively. Bouws and Komen (1983) also found that the magnitudes of wind and whitecapping are of the same magnitude, with their wind about $25 \%$ higher compared to $12 \%$ in this study. Based on their Fig. 3, it can be found that the magnitude of the absolute value of the nonlinear interaction term is about $30 \%$ of the wind input magnitude whereas in 
Fig. 6 Spatial variation of source term magnitudes $M$ for wind input (upper left panel), absolute value of whitecapping dissipation (upper right panel), four-wave interaction (lower left panel) and bottom friction (lower right panel) for 5 December 2013, 15:00 h
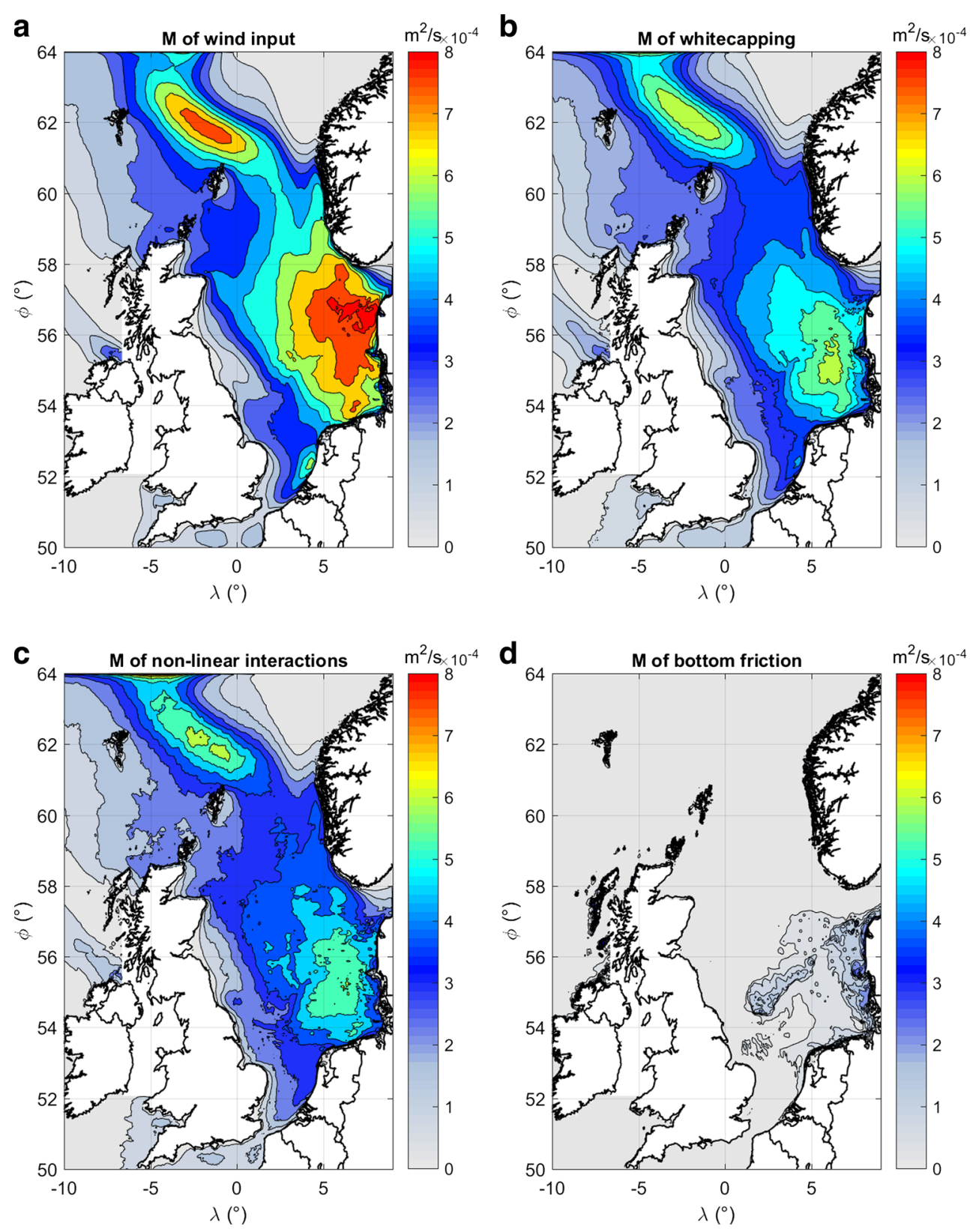

this study they are almost equal in magnitude. This may be due to the fact that Bouws and Komen (1983) estimated this term with an exact method instead of the approximate DIA in this study. Further, their magnitude of the bottom friction term is of the same order as the whitecapping magnitude, which is much higher than in the present study. This is partly due to their higher value $\left(C_{f, J O N}=0.067 \mathrm{~m}^{2} \mathrm{~s}^{-3}\right)$ of the bottom friction coefficient. An explanation of these differences is difficult to give on the basis of the present results, only a re-hindcast of January 1976 could do.

Of further interest for our analysis is to investigate this balance for a deeper and a shallower location. To that end, results were extracted and presented in Fig. 8 for location North Cormorant (NCO) with a water depth of about
$160 \mathrm{~m}$ and location Wielingen (WIEL) close to the Dutch coast with a water depth (at still water) of $8 \mathrm{~m}$.

In comparison to the inter-mediate depth location K13, bottom friction does not play a role at location North Cormorant (NCO) and wind input, whitecapping and nonlinear interactions have almost the same magnitudes. At the shallow water location Wielingen (WIEL), the source term balance has changed dramatically. Now bottom friction and depth limited wave breaking are dominant over whitecapping dissipation. Wind input is the most dominant source term and the magnitude of the nonlinear four-wave interactions is about half as strong as wind input.

So far, a straightforward analysis has been performed on the results of the non-stationary SWAN simulations to 


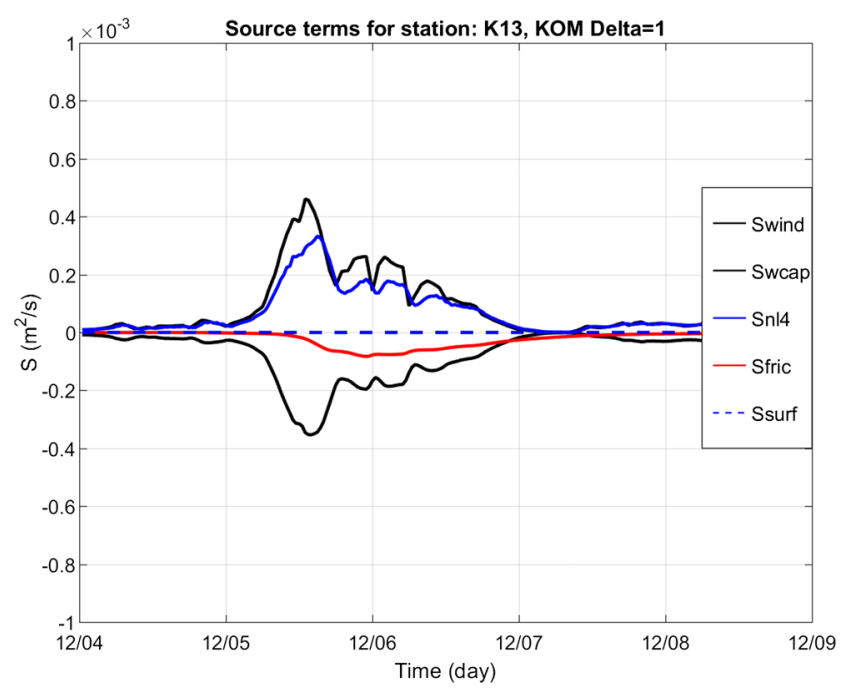

Fig. 7 Temporal variation of source term magnitudes $M$ using the Komen formulation with $\delta=1$ for the December 2013 storm at location K13. $S_{\text {wind }}$ (black line), $S_{\text {wcap }}$ (black line), $S_{\mathrm{n} 14}$ (blue line), $S_{\text {fric }}$ (red line), $S_{\text {brk }}$ (black dashed line)

reveal the source balance at three locations with various depths. The next step was to use these analysis techniques on the SWAN model runs with different physical settings. Although many different settings can be tested, the present analysis is restricted to four variations; setting the parameter $\delta$ in the whitecapping formulation; applying the saturation based whitecapping formulation of Van der Westhuysen et al. (2007); the recently developed observation-based whitecapping formulation by Rogers et al. (2012) and Zieger et al. (2015), and increasing the bottom friction coefficient to $\mathrm{m}^{2} \mathrm{~s}^{-3}$.

a

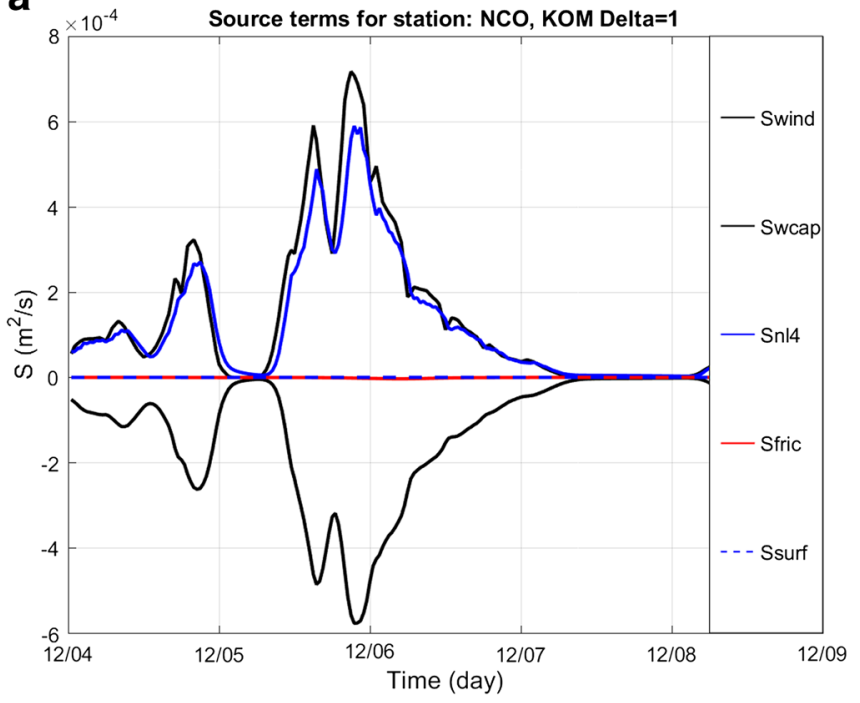

The effect of these different source term packages on the evolution of the significant wave height $H_{m 0}$, the lowfrequency wave height $H_{E 10}$ and the spectral period $T_{m-1,0}$ is shown in Fig. 9. Statistical information is summarized in Table 2 based on a three day period from 5 Dec. 2013, 0:00 h till 8 Dec. 2013, 0:00 h. For the statistical analysis, measured and computed data are collocated in time on the basis of the 3-hourly measurement points, each based on a time series of 20-min duration.

The results for the Komen type whitecapping using $\delta=0$ show a significant under-prediction of the significant wave height $H_{m 0}$, the percentage of low-frequency wave height $H_{E 10}$ and the spectral period $T_{m-1,0}$ compared to the buoy observations, but also in comparison to the results of the default SWAN settings, as shown in Table 2. This result is due to an increased dissipation rate at lower frequencies. This poorer performance of this setting for the whitecapping dissipation is consistent with the finding of Rogers et al. (2003) and Pallares et al. (2014). It is also the motivation of the SWAN team to have $\delta=1$ as the default setting for whitecapping until a better and well tested alternative is available.

The effect of increasing the JONSWAP bottom friction coefficient from $C_{f, J O N}=0.038 \mathrm{~m}^{2} \mathrm{~s}^{-3}$ to $C_{f, J O N}=0.067$ $\mathrm{m}^{2} \mathrm{~s}^{-3}$ on model performance (upper right panel) also shows an under-prediction of wave heights and the wave period. Compared to the results of the $\delta=0$ setting, the under-prediction of the percentage of low-frequency wave height $H_{E 10}$ and the spectral period $T_{m-1,0}$ is even worse. As expected bottom friction is more effective on the lower frequency components than on the higher frequency components. The high value for the bottom friction coefficient was

Fig. 8 Temporal variation of source term magnitudes for the December 2013 storm at location NCO (left panel) and WIEL (right panel). $S_{\text {wind }}$ (black line), $S_{\text {wcap }}$ (black line), $S_{\text {wcap }}$ (blue line), $S_{\text {frc }}$ (red line), $S_{\text {brk }}$ (black dashed line) 
Fig. 9 Temporal variation of observed (black lines) and computed significant wave height $H_{\mathrm{m} 0}$ (upper panel), percentage of low-frequency wave height $H_{\mathrm{E} 10}$ with respect to $H_{m 0}$ (middle panel), and the spectral period $T_{\mathrm{m}-1,0}$ (lower panel) for the December 2013 storm at location K13. Results for $\delta=1$ (red dashed line), $\delta=0$ (black dash-dot line), $C_{f, J O N}=0.067 \mathrm{~m}^{2} \mathrm{~s}^{-3}$ (red dash-dot line), ST6 whitecapping (black dashed line) and Westhuysen whitecapping (red line)
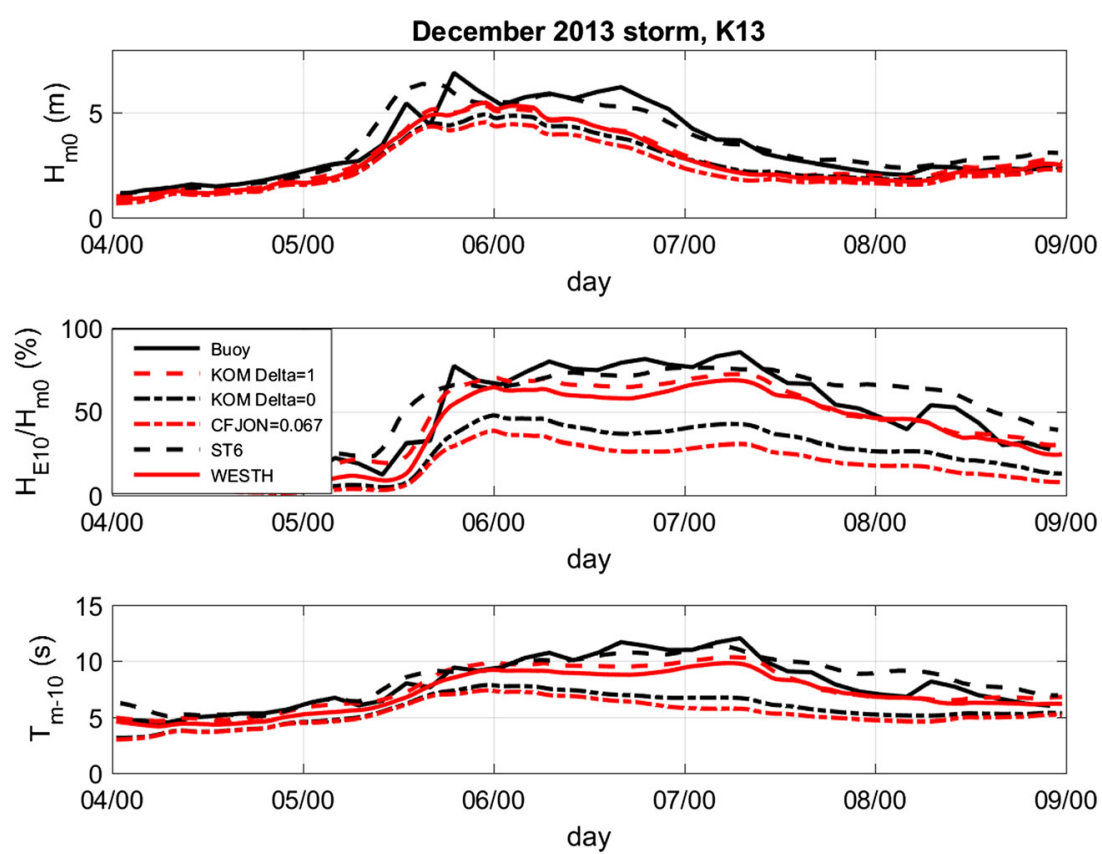

originally introduced by Bouws and Komen (1983) and differed from the low value as recommended for swell waves on the basis of the JONSWAP project (cf. Hasselmann et al. 1973). Zijlema et al. (2012), however, showed that there is no reason to have different values for the JONSWAP bottom friction coefficient, one for wind seas and one for swell. The results shown in the Fig. 9 support the choice to have one lower value for the JONSWAP bottom friction coefficient applicable to both wind sea and swell conditions.

The results for the Van der Westhuysen et al. (2007) whitecapping formulation show a slightly stronger underprediction than the default $\delta=1$ setting. This is also reflected in the BIAS and RMSE values for all three wave parameters. The best results are obtained with the ST6 whitecapping formulation. The biggest improvement is for the wave height values, where the initially strong underprediction is reversed to a slight over-prediction. For the spectral wave period $T_{m-1,0}$, however, the initially large under-prediction is now a slightly lower over-prediction and the RMSE for the wave period is slightly higher than for the default case with the $\delta=1$ setting. Inspection of Fig. 9 shows that the ST6 is especially working well during the period around the peak of the storm, the largest deviations occur around noon on December 5 , and after the peak of the storm around 8 December 2013, 0:00 h.

The first step towards explaining these differences is to inspect the source term balance for this storm. To that end, the temporal variation of source term magnitudes is shown in Fig. 10 for the $\delta=0$ setting (upper left panel), the increased bottom friction (upper right panel), the Westhuysen setting (lower left panel) and the ST6 setting
Table 2 Bias and RMSE of significant wave height $H_{\mathrm{m} 0}$, lowfrequency wave height $H_{\mathrm{E} 10}$ and spectral period $T_{m-1,0}$ of SWAN using different physical source term packages for the December 2013 storm at K13 location. The time interval for collocating points is from 5 December 2013, 0:00 hours till 8 December 2013, 0:00 hours

\begin{tabular}{|c|c|c|c|c|c|c|}
\hline & \multicolumn{3}{|l|}{ BIAS } & \multicolumn{3}{|l|}{ RMSE } \\
\hline & $H_{\mathrm{m} 0}(m)$ & $H_{\mathrm{E} 10}(m)$ & $T_{\mathrm{m}-1,0}(s)$ & $H_{\mathrm{m} 0}(m)$ & $H_{\mathrm{E} 10}(m)$ & $T_{\mathrm{m}-10}(s)$ \\
\hline$\delta=1$ & -0.59 & -0.54 & -0.46 & 0.91 & 0.93 & 0.84 \\
\hline$\delta=0$ & -0.82 & -1.17 & -2.30 & 1.08 & 1.60 & 2.64 \\
\hline$C_{f}=0.067$ & -1.04 & -1.42 & -2.69 & 1.31 & 1.90 & 3.10 \\
\hline Westh & -0.69 & -0.71 & -0.92 & 0.95 & 1.07 & 1.18 \\
\hline ST6 & 0.09 & 0.12 & 0.40 & 0.55 & 0.69 & 0.88 \\
\hline
\end{tabular}



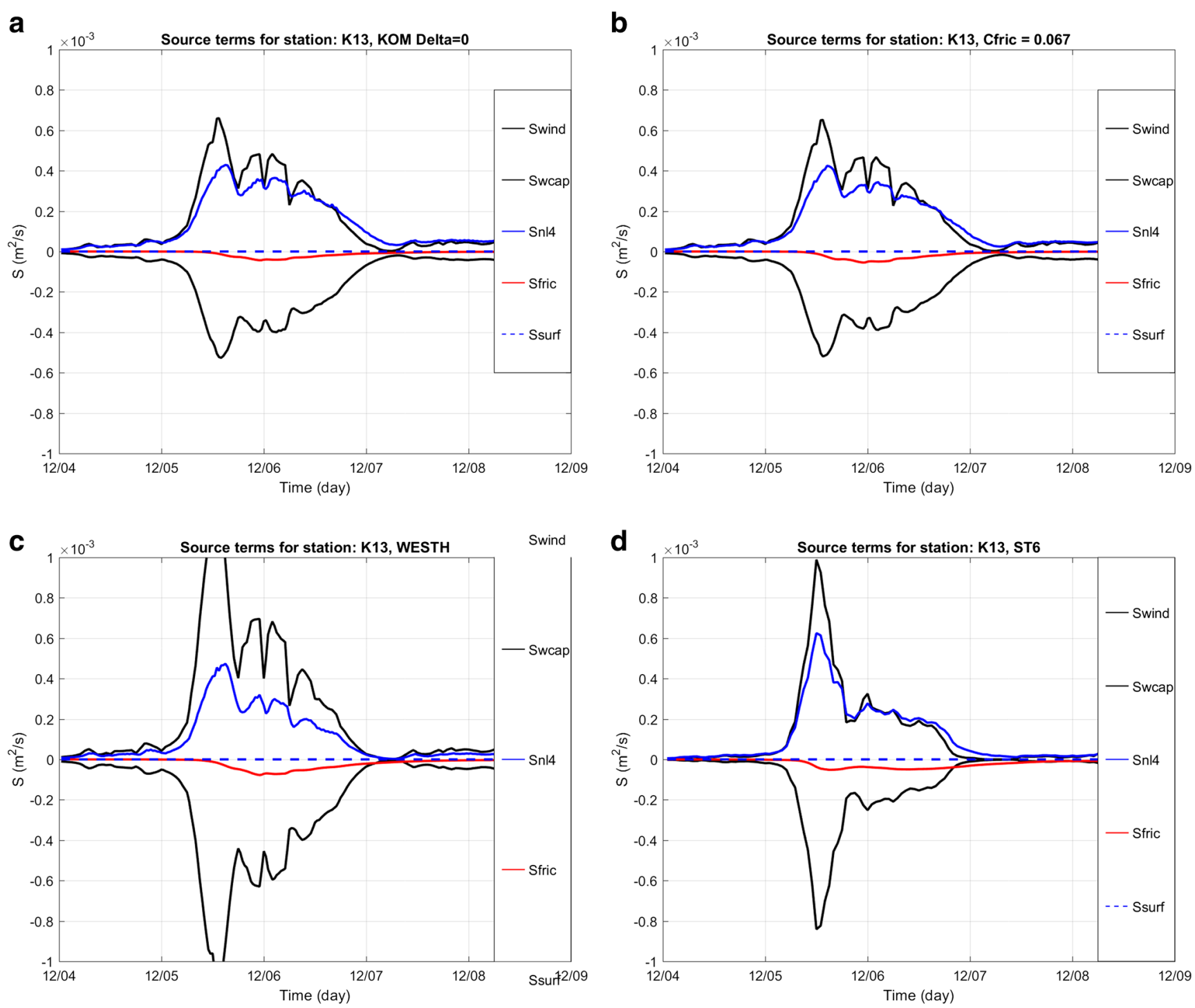

Fig. 10 Temporal variation of source term magnitudes $M$ for the December 2013 storm at location K13. $S_{\text {wind }}$ (black line), $S_{\text {wcap }}$ (black line), $S_{\mathrm{n} 14}$ (blue line), $S_{\text {fric }}$ (red line), $S_{\text {brk }}$ (black dashed line). Results

(lower right panel). To help comparing the results, the $y$-axis is equal for all panels. It is noted that the peak of the Westhuysen wind input magnitude is at a level $1.2 \times 10^{-3} \mathrm{~m}^{2} \mathrm{~s}^{-1}$, which is slightly out of scale.

The results in the upper panels are very similar in shape and magnitude. Compared to the magnitudes of the base case (Fig. 7), all magnitudes, except for bottom friction, are about $40 \%$ higher. The main differences are in the negative peak values of the bottom friction magnitude: $M_{\text {fric }}=$ $-0.77 \times 10^{-4} \mathrm{~m}^{2} \mathrm{~s}^{-1}$ for the default case with $\delta=0$, $M_{\text {fric }}=-0.37 \times 10^{-4} \mathrm{~m}^{2} \mathrm{~s}^{-1}$ for the case with $\delta=1$ and $M_{\text {fric }}=-0.46 \times 10^{-4} \mathrm{~m}^{2} \mathrm{~s}^{-1}$ for the case with a higher bottom friction. The notion that the peak of the bottom fric- for $\delta=0$ (upper left panel), $C_{f, J O N}=0.067 \mathrm{~m}^{2} \mathrm{~s}^{-3}$ (upper right panel), Westhuysen (lower left panel) and ST6 (lower right panel)

tion magnitude becomes lower when the bottom friction coefficient is increased may appear counter-intuitive. This, however, is due to the fact that the variance density is much lower due to energy losses in up-wave directions.

The source term balance for the Westhuysen setting shows a much higher wind input and whitecapping dissipation magnitudes than for the cases with with the Komentype dissipation ( $\delta=0$ and $\delta=1)$, whereas the magnitude of the nonlinear four-wave interaction term is almost equal to the one for the case with $\delta=0$ and $40 \%$ higher than for the case with $\delta=1$. The minimum bottom friction magnitude is slightly lower, $M_{\text {fric }}=-0.67 \times 10^{-4} \mathrm{~m}^{2} \mathrm{~s}^{-1}$, than for the default case with $\delta=1$. 
Fig. 11 Observed and computed variance density spectra (left panel) and computed whitecapping source term (right panel) at 6 December 2013, 12:00 h at location K13
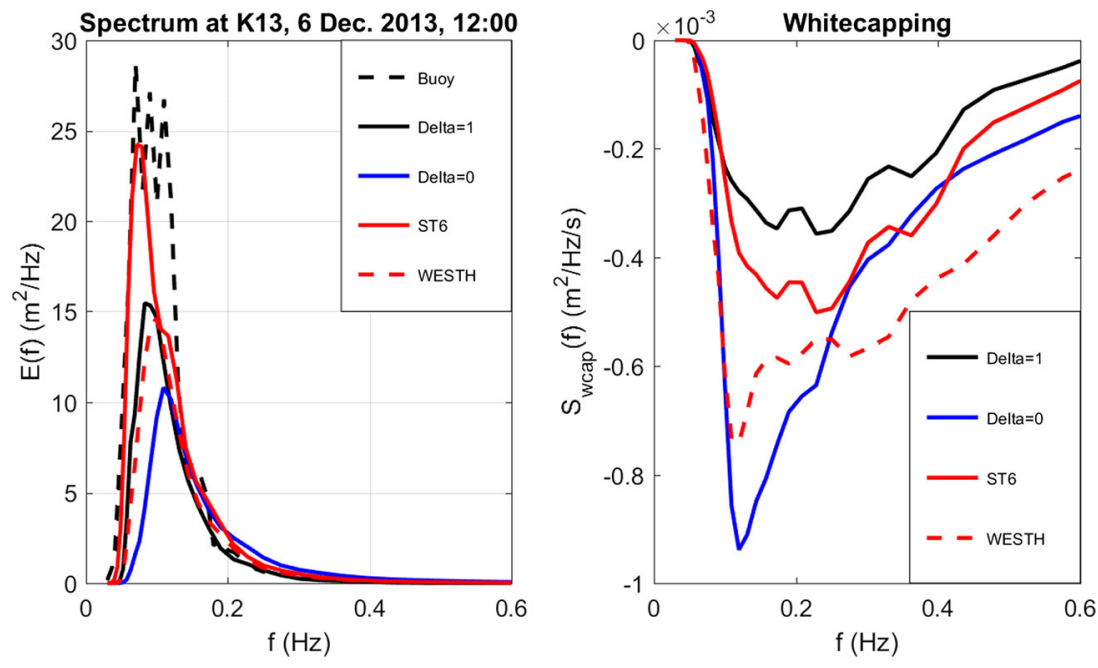

The most pronounced differences with all other settings, as considered in this analysis, occur for the ST6 setting. Compared to the default setting with $\delta=1$, it can be seen that the source magnitudes for wind input, whitecapping and nonlinear four-wave interaction are all about twice as high, whereas, the negative peak of the bottom friction magnitude is only slightly higher with a value of $M_{\text {fric }}=$ $-0.84 \times 10^{-4} \mathrm{~m}^{2} \mathrm{~s}^{-1}$. A striking difference is in the shape of the time variation of source term magnitudes, it is much more peaked at the peak of the storm around noon on 5 December 2013.

An explanation for this behaviour is difficult to give, as the various source terms all affect each other. A first step is to show the variance spectra and corresponding source terms for whitecapping dissipation for a moment of time during the storm. Figure 11 gives this spectral information for a moment of time after the peak of the storm, on 6 Dec. 2013, 12:00 $\mathrm{h}$ for all five considered source term packages, except for the case with increasing bottom friction. The left panel with the wave spectra are supplemented with the observed spectrum (largest peak, black).

The results in the left panel of Fig. 11 clearly show that the wave spectrum computed with the ST6 setting is closest to the observed spectrum although its frequency width is under-estimated, with the default $\delta=1$ and Westhuysen settings being similar but at a lower level. The poorest agreement is for the setting with $\delta=0$. The most important feature of the ST6 based spectrum is its good prediction of the variance density at the fore-flank of the wave spectrum, i.e. for $f<0.1 \mathrm{~Hz}$. This is primarily due to its lower amount of whitecapping dissipation in this frequency range. For the higher frequencies, the shape of the ST6 whitecapping source term is similar but stronger to the one of the default setting with $\delta=1$. Significant differences in source term magnitude occur for the $\delta=0$ and the Westhuysen setting, which show a much stronger whitecapping rate.

\section{Summary and conclusions}

In the present study, the source balance of wind-generated waves was investigated in relation to the effects of applying different source term packages on the prediction of significant wave height $H_{\mathrm{m} 0}$, the low-frequency wave height $H_{\mathrm{E} 10}$ and the spectral period $T_{m-1,0}$. This analysis was performed with the third-generation wave SWAN model 41.10 to hindcast the severe winter storm of December 2013 hitting north-west Europe. In our analysis, we used the recently added functionality of the SWAN model to output source term magnitudes in all grid points, either as spatial fields (BLOCK output) or in tables at selected output points. Individual spectra and source terms were also output at selected TEST locations.

The performance of SWAN was quantified by comparing the results against buoy measurements at location K13 in the southern North Sea. Of particular, interest was the ability of several source terms within SWAN to properly predict the low-frequency wave height $H_{\mathrm{E} 10}$, which is of interest for large ships sailing in the dredged entrance channel towards the Port of Rotterdam. These low-frequency components are difficult to predict using Komen type whitecapping dissipation formulations as these use an overall mean wave steepness to scale the whitecapping dissipation in proportion to the amount of variance density in the spectrum. As discussed in the introduction, this approach is inaccurate in situations with multi-peaked spectra, for instance in case of a background swell and a local wind sea. In the southern North Sea, a significant amount of low-frequency energy, i.e. for $f<0.1 \mathrm{~Hz}$, is usually part of a wind sea system, whereas pure swell cases without a significant wind sea seldom occur. Still, the amount of low-frequency energy is usually under-predicted. In order to improve the prediction of this low-frequency energy Rogers et al. (2003) recommended to set $\delta=1$ in the Komen-type whitecapping 
dissipation. Pallares et al. (2014) came to a similar conclusion. These results led the SWAN team to choose $\delta=1$ as the default setting for the SWAN model.

In this study, two new whitecapping formulations were applied that differ in a fundamental way from the Komen type whitecapping. The Westhuysen setting applies a local saturation-based whitecapping formulation that remedies part of the drawbacks of using an overall mean wave steepness, whereas the recently developed ST6 formulation uses an alternative method with both a local saturation spectrum and a cumulative effect in which breaking at a certain frequency component is affected by all lower frequency components. It turned out that the Westhuysen formulation is comparable in model performance with the Komen type whitecapping with $\delta=1$. A significant improvement is made with the ST6 formulation. The significant wave height $H_{\mathrm{m} 0}$, low-frequency wave height $H_{\mathrm{E} 10}$ and the spectral period $T_{m-1,0}$ correspond better with measurements. This preliminary finding suggests that the ST6 whitecapping (and wind) formulation works on North Sea scale. As the ST6 formulation is also available in the WAVEWATCH III model, including ST6 in SWAN will yield a consistent way of nesting from ocean scales (for which WAVEWATCH III is optimal, due to its explicit scheme) to coastal scales where SWANs implicit scheme is effective for operational applications at high spatial resolutions.

Choosing the JONSWAP bottom friction coefficient equal to $C_{f, J O N}=0.038 \mathrm{~m}^{2} \mathrm{~s}^{-3}$, as recommended by Zijlema et al. (2012), also seems a better choice than the previously recommended value for wind seas of $C_{f, J O N}=$ $0.067 \mathrm{~m}^{2} \mathrm{~s}^{-3}$, as originally recommended by Bouws and Komen (1983). It turned out that bottom friction is more effective for lower frequency components than for higher frequency components of the wave spectrum. In the present analysis, the JONSWAP bottom friction formulation has been used in combination with assuming a constant coefficient (or bottom roughness) for the whole North Sea. Further improvements may be made by applying other bottom friction formulations like the one by Madsen et al. (1988), or the recently developed one by Smith et al. (2011), but also by applying spatially varying bottom characteristics, but these, however, are not yet available.

The recently developed ST4 and ST6 source term packages include a source term for swell dissipation due to other processes than whitecapping and wave breaking. Ardhuin et al. (2010) and Zieger et al. (2015) propose source terms for this process, but these are probably not relevant in North Sea conditions which are not dominated by swell.

The analysis of source term magnitudes shows that on deep water, at location NCO, wind input, whitecapping dissipation and nonlinear four-wave interactions are of similar magnitude. In inter-mediate depth, at location K13, this balance is slightly different with a significant but not dominant role for whitecapping. This result is in general agreement with the finding by Bouws and Komen (1983) although some quantitative differences exists. A re-hindcast of the January 1976 storm could provide an explanation of these differences. As expected, at the shallow water location WIEL, bottom friction and depth-limited wave breaking are dominant over whitecapping dissipation

The main conclusion of this study is that the ST6 source term package gives the best SWAN model performance for the December 2013 storm in terms of the significant wave height $H_{\mathrm{m} 0}$, the low-frequency wave height $H_{\mathrm{E} 10}$, the spectral period $T_{\mathrm{m}-1,0}$ and the spectral shape. Based on this result, it is recommended to further test the performance of this source term package for additional storms and additional locations. Another conclusion is that, wind input and whitecapping dissipation are of the same magnitude in deep and intermediate water depth, as well as the non-linear transfer rate due to four-wave interactions. In the southern North Sea, bottom friction becomes a significant dissipation process. Presenting the spatial- and frequencydependent source term, magnitudes provides a useful tool to inter-compare model performance.

\section{Recommendations}

To proceed, it is noted that the present study was restricted to one storm, one location to validate model results and a spatial resolution which is sufficiently fine for North Sea applications but not for shallow coastal regions. Adding more storms and locations to validate wave model performance is therefore a logical next step for further analyses. Improving the spatial resolution in the coastal areas will enable analysing in more detail the source term balance for shallow water and investigate the role recently developed surf breaking and triad interaction formulations. This can simply be done using unstructured grids down to resolutions in the order of $25 \mathrm{~m}$ (e.g. Dietrich et al. 2013). Such an approach, however, can only be done in conjunction with more accurate forecasts of water levels and currents. This can be achieved by, e.g. a tightly coupled ADCIRCSWAN setup in combination with the Madsen et al. (1988) bottom friction formulation for consistency reasons. Further improvements are possible by incorporating and testing recent developments in bottom friction (cf. Smith et al. 2011), the so-named ST4 whitecapping formulation of Ardhuin et al. (2010) and more advanced solvers for nonlinear interaction four-wave interactions (Van Vledder 2006, 2012; Tolman 2013) and for the three-wave interactions (Salmon et al. 2016). 
Acknowledgments Part of this work has been funded by ONR Grants N00014-10-1-0453 and N00014-12-1-0534. Buoy data were kindly provided by Rijkswaterstaat in the Netherlands and the Dutch Royal Meteorological Institute (KNMI). Currents and water levels were kindly provided by Deltares.

Open Access This article is distributed under the terms of the Creative Commons Attribution 4.0 International License (http:// creativecommons.org/licenses/by/4.0/), which permits unrestricted use, distribution, and reproduction in any medium, provided you give appropriate credit to the original author(s) and the source, provide a link to the Creative Commons license, and indicate if changes were made.

\section{Appendix A: Summaryof physical settings SWAN model}

\begin{tabular}{ll}
\hline SWAN runs & Commands in input file \\
\hline SWAN runs & Commands in input file \\
$\delta=1$ & GEN3 KOM \\
& WCAP KOM DELTA $=1$ \\
& FRIC JONSWAP 0.038 \\
& BREA CONST 1.00 .73 \\
$\delta=0$ & GEN3 KOM \\
& WCAP KOM DELTA $=0$ \\
& FRIC JONSWAP 0.038 \\
& BREA CONST 1.0 0.73 \\
CFJON=0.067 & GEN3 KOM \\
& WCAP KOM DELTA=1 \\
& FRIC JONSWAP 0.067 \\
& BREA CONST 1.0 0.73 \\
WESTH & GEN3 WESTH \\
& FRIC JONSWAP 0.038 \\
ST6 & BREA CONST 1.0 0.73 \\
& GEN3 BAB 4.7E-7 6.6E-6 4.0 4.0 \\
& 1.2 0.0020 UP VECTAU AGROW \\
& FRIC JONSWAP 0.038
\end{tabular}

\section{References}

Alves JHGM, Banner ML (2003) Performance of a saturation-based dissipation rate source term in modelling the fetch-limited evolution of wind waves. J Phys Oceanogr 33:1274-1298

Ardhuin F, Chapron B, Collard F (2009) Observation of swell dissipation across oceans. Geophys. Res. Lett. L06607(2009):36. doi:10.1029/2008GL037030

Ardhuin F, Rogers WE, Babanin AV, Filipot J-F, Magne R, Roland A, Van der Westhuysen AJ, Queffeulou P, Lefevre JM, Aouf L, Collard F (2010) Semi-empirical dissipation source functions for ocean waves. Part I: definition, calibration, and validation. J Phys Oceanogr 40:1917-1941

Ardhuin F, Dumas F, Bennis AC, Roland A, Sentchev A, Forget P, Wolf J, Girard F, Osuna P, Benoit M (2012) Numerical wave modeling in conditions with strong currents: dissipation, refraction and relative wind. J Phys Oceanogr 42:2101-2120

Babanin AV, Tsagareli KN, Young IR, Walker DJ (2010) Numerical Investigation of Spectral Evolution of Wind waves. Part II: Dissipation Term and Evolution Tests. J. Phys. Oceanogr. 40:667-683. doi:10.1175/2009JPO4370.1

Banner M, Jones ISF, Trinder JC (1989) Wavenumber spectra of short gravity waves. J Fluid Mech 198:321-344

Battjes JA, Janssen JPFM (1978) Energy loss and set-up due to breaking of random waves. In: Proceedings 16th international conference Coastal Engineering, ASCE, Hamburg, 569-587

Blake RA (1991) The dependence of wind stress on wave height and wind speed. J Geophys Res 96(C11):20531-20545

Booij N, Ris RC, Holthuijsen LH (1999) A third-generation wave model for coastal regions, Part i, Model description and validation. J Geoph Res 104(C4):7649-7666

Bouws E, Komen GJ (1983) On the balance between growth and dissipation in a depth-limited wind-sea in the Southern North Sea. J Phys Oceanogr 13:1653-1658

Cavaleri L, Bertotti L (2004) Accuracy of the modeled wind and wave fields in enclosed seas. Tellus 56A:167-175

Dietrich JC, Zijlema M, Allier PE, Holthuijsen LH, Booij N, Meixner JD, Proft JK, Dawson CN, Bender CJ, Naimaster A, Smith J, Westerink JJ (2013) Limiters for spectral propagation velocities in SWAN. Ocean Model 70:85-102

Donelan MA, Babanin AV, Young IR, Banner ML, McCormick C (2005) Wave follower field measurements of the wind-input spectral function. PartI: measurements and calibrations. J Atmos Ocean Technol 22:1672-1689

Donelan MA, Babanin AV, Young IR, Banner ML (2006) Wavefollower field measurements of the wind-input spectral function. Part II: parameterization of the wind input. J Phys Oceanogr 36:1672-1689

Eldeberky Y (1996) Nonlinear transformations of wave spectra in the nearshore zone. Ph.D Thesis, Fac. of Civil Engineering, Delft University of Technology, The Netherlands, 203pp

Günther H, Hasselmann S, Janssen PAEM (1992) The WAM model Cycle 4 (revised version), Deutsch. Klim. Rechenzentrum, Techn. Rep. No. 4

Hasselmann K, Barnett T, Bouws E, Carlson H, Cartwright D, Enke K, Ewing J, Gienapp H, Hasselmann D, Kruseman P, Meerburg A, Muller P, Olbers D, Richter K, Sell KW, Walden H (1973) Measurements of wind-wave growth and swell decay during the JOint North Sea WAve Project (JONSWAP). Dtsch Hydrogh Z Suppl A8:95

Hasselmann K (1974) On the spectral dissipation of ocean waves due to white capping. Bound.-Layer Meteorol. 6(1-2):107-127

Hasselmann S, Hasselmann K, Allender JH, Barnett TP (1985) Computations and parameterizations of the nonlinear energy transfer in a gravity-wave spectrum. Part II parameterizations of the nonlinear energy transfer for application in wave models. J Phys Oceanogr 15:1378-1391

Holthuijsen LH, Zijlema M, van der Ham PJ (2008) Wave physics in a tidal inlet. In: Proceedings 31th international conference on Coastal Engineering, pp 12. Hamburg, Germany:12

Holthuijsen LH, Powell MD, Pietrzak JD (2012) Wind and waves in extreme hurricanes. J Geophs Res 117:C09003. doi: $10.1029 / 2012 J C 007983$

Hulst S, van Vledder GPh (2013) CFSR Surface wind calibration for wave modeling purposes. In: Proceedings 13th International Workshop on Wave Hindcasting and Forecasting and 4th Coastal Hazards Symposium. 27-Oct-1 Nov. 2013, Banff, Canada. www. waveworkshop.org

Hurdle DP, van Vledder GPh (2004) Improved spectral wave modelling of white-capping dissipation in swell sea systems. In: 
Proceedings 23rd international conference on Offshore Mech and Arctic Eng. Paper OMAE2004-51562

Hwang PA (2011) A note on the ocean surface roughness spectrum. J Atmos Ocean Tech 28:436-442

Janssen PAEM (1991) Quasi-linear theory of wind-wave generation applied to wave forecasting. J. Phys. Oceanogr. 19:745-754

Khandekar ML, Lalbeharry R, Cardone VJ (1993) The performance of the Canadian Spectral Ocean Wave Model (CSOWM) During the Grand Banks ERS-1 SAR Wave Spectra Validation Experiment. Atmophere-Ocean 32(1):31-60

Komen GJ, Hasselmann S, Hasselmann K (1984) On the existence of a fully developed wind-sea spectrum. J Phys Oceanogr 14:1271-1285

Komen GJ, Cavaleri L, Donelan M, Hasselmann K, Janssen PAEM (1994) Dynamics and Modelling of Ocean Waves. Cambridge University Press

Leckler F, Ardhuin F, Filipot J-F, Mironov A (2013) Dissipation source terms and white cap statistics. Ocean Model 70:62-74

Madsen OS, Poon YK, Graber HC (1988) Spectral wave attenuation by bottom friction: Theory Proceedings 21st international conference Coastal Engineering. ASCE:492-504

Melville WK, Verron F, White CJ (2002) The velocity field under breaking waves: coherent structures and turbulence. J Fluid Mech 454:203-233

Morris J, Gautier C, van Vledder GPh (2015) Wave growth at short fetches. In: Proceedings 36th IAHR World Congress, The Hague, The Netherlands

Pallares E, Süchez-Arcilla A, Espino M (2014) Wave energy balance in wave models (SWAN) for semi-enclosed domains - Application to the Catalan coast. Cont Shelf Res 87:41-53

Pierson WJ, Moskowitz L (1964) A proposed spectral form for fully developed wind seas based on the similarity theory of S. A. Kitaigorodskii. JGeophys Res 69:5181-5190

Powell MD, Vickery PJ, Reinhold TA (2003) Reduced drag coefficient for high wind speeds in tropical cyclones. Nature 422:279-283

Rogers WJ, Hwang PA, Wang DW (2003) Investigation of wave growth and decay in the SWAN model: three Regional-Scale applications. J Phys Oceanogr 33:366-389

Rogers WE, Babanin AV, Wang DW (2012) Observation-consistent input and whitecapping -dissipation in a model for wind-generated surface waves: description and simple calculations. J Atmos Ocean Technol 29:1329-1346

Roland A, Ardhuin F (2014) On the developments of spectral wave models: numerics and parameterizations for the coastal ocean Ocean Dynamics 64:833-846. doi:10.1007/s10236-014-0711-z

Saha S et al (2010) The NCEP climate forecast system reanalysis. Bulletin american meteorological society, pp 1015-1057 doi:10.1175/2010BAMS 3001.1

Salmon JE, Holthuijsen LH, Zijlema M, van Vledder GPh, Pietrzak JD (2015) Scaling depth-induced wave-breaking in two-dimensional spectral wave models. Ocean Model 87:30-47. doi:10.1016/j.ocemod.2014.12.011

Salmon J, Smit PB, Janssen TT, Holthuijsen LH (2016) A consistent collinear triad approximation for operational wave models. Accepted for Ocean Modelling

Smith A, Babanin AV, Riedel P, Young IR, Oliver S, Hubbert G (2011) Introduction of a new friction routine into the SWAN model that evaluates roughness due to bedform and sediment size changes. Coast Eng 58:317-326

Snyder RL, Dobson FW, Elliott JA, Long RB (1981) Array measurement of atmospheric pressure fluctuations above surface gravity waves. J Fluid Mech 102:1-59

SWAN team (2016) WAN 41.10, Technical Manual. http://www.swan. tudelft.nl
Taylor PA, Lee RJ (1984) Simple guidelines for estimating wind speed variation due to small scale topographic features. Climatol Bull 18:3-32

Tolman HL, Chalikov D (1996) Source terms in a third-generation wind wave model. J Phys Oceanogr 26:2497-2518

Tolman HL (2009) User manual and system documentation of WAVEWATCH III version 3.14. Techn. Note 276, NOAA/NWS/NCEP/MMAB, 194 pp. + appendices

Tolman HL (2012) A Generalized Multiple Discrete Interaction Approximation for resonant four-wave nonlinear interactions in wind wave models with arbitrary depth. Ocean Modelling 70:1124

Tolman HL, Grumbine RW (2012) Optimization of a generalized multiple discrete interaction approximation for wind waves at arbitrary depth. Ocean Model 70:25-37

Tolman HL, Banner ML, Kaihatu JM (2013) The NOPP operational wave model improvement project. Ocean Model 70:2-10

Tolman HL et al (2014) User manual and system documentation of WAVEWATCH III version 4.18

Van Vledder GPh (2001) Extension of the discrete interaction approximation for computing quadruplet wave-wave interactions in operational wave prediction models. In: Proceedings 4th ASCE international symposium on Ocean Waves Measurement and Analysis

Van Vledder G (2006) The WRT method for the computation of nonlinear four-wave interactions in discrete spectral wave models. Coast Eng 53:223-242

Van Vledder G (2012) Efficient algorithms for computing non-linear four-wave interactions. ECMWF Workshop on Ocean Waves, pp $25-27$

Van Vledder G, Herbers THC, Jensen RE, Resio DT, Tracy B (2000) Modelling of non-linear quadruplet wave-wave interaction in operational wave models. In: Proceedings 27th international conference on Coastal Engineering, Sydney, Australia

Van der Westhuysen AJ, Zijlema M, Battjes JA (2007) Saturation based whitecapping dissipation in SWAN for deep and shallow water. Coastal Eng 54:151-170

Van der Westhuysen AJ, van Dongeren AR, Groeneweg J, van Vledder GPh, Peters H, Gautier C, van Nieuwkoop JCC (2012) Improvements in spectral wave modelling in tidal inlets. J Geophys Res 117(C00J28). doi:10.1029/2011JC007837

WAMDI (1988) A third-generation ocean wave prediction model. J Phys Oceanogr 18:1775-1810

Wu J (1982) Wind-Stress Coefficients Over Sea Surface From Breeze to Hurricane. J. Geophys. Res. 87(C12):9704-9706

Young IR, van Vledder GPh (1993) The central role of nonlinear wave interactions in wind-wave evolution. Philos Trans R Soc London 342:505-524

Young IR, Babanin AV (2006) Spectral distribution of energy dissipation of wind-generated waves due to dominant wave breaking. J Phys Oceanogr 36:376-394

Zieger S, Babanin AV, Rogers WE, Young IR (2015) Observationbased source terms in the third-generation wave model WAVEWATCH. Virtual Special Issue on Ocean Surface Waves. Ocean Model 96:2-25

Zijlema M., Van der Westhuysen AJ (2005) On convergence behaviour and numerical accuracy in stationary SWAN simulations of nearshore wind wave spectra. Coast Eng 52:237-256

Zijlema M, van Vledder GPh, Holthuijsen LH (2012) Bottom friction and wind drag for wave models. Coast Eng 65:19-26

Zweers N, Makin VK, de Vries JW, Kudryavtsev VN (2015) The impact of Spray-Mediated Enhanced Enthalphy and Reduced Drag Coefficients in the Modelling of Tropical Cyclones BoundaryLayer Meteorology 155:501-14. doi:10.1007/s10546-014-9996-1 